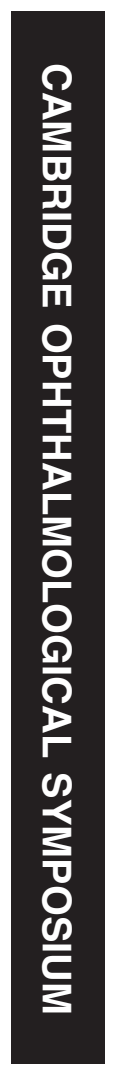

\title{
The role of the posterior ciliary body in the biosynthesis of vitreous humour
}

\begin{abstract}
Recently, several groups have published new information regarding the origins and structure of the vitreous humour, and the inner limiting lamina (ILL) of the retina. This short article provides an overview of this new information. It is proposed that vitreous proteins are derived from several different cell types with the posterior half of the non-pigmented ciliary epithelium being prominent in the expression of several connective tissue macromolecules. In addition, some basement membrane macromolecules are also expressed by the ciliary body and may subsequently be assembled on the surface of the Müller cells to form the ILL. New data suggest that the posterior half of the non-pigmented ciliary epithelium has substantial secretory activity and is likely to play a pivotal role in eye development.

Eye (2002) 16, 454-460. doi:10.1038/

sj.eye. 6700199
\end{abstract}

Keywords: ciliary body; non-pigmented ciliary epithelium; collagen; opticin; vitrin

\section{Introduction}

In this review, current concepts of the origin of the connective tissue macromolecules present in the vitreous and the inner limiting lamina of the retina will be presented.

Correspondence:

R Mayne

University of Alabama at

Birmingham

Department of Cell Biology

1530 3rd Ave S

MCLM Box 88

Birmingham

AL 35294-0005, USA

Tel: 205 934-2053

Fax: 205 934-0950

E-mail: rmayne@uab.edu
PN Bishop ${ }^{1}$, M Takanosu², M le Goff ${ }^{1}$ and R Mayne ${ }^{2}$ located in the vitreous cortex and basal vitreous that are probably members of the macrophage/monocyte lineage. ${ }^{1}$ The gel-like nature of the vitreous humour is maintained by a dilute meshwork of collagen fibrils. ${ }^{2-4}$ These long, thin fibrils (typically $12-15 \mathrm{~nm}$ in diameter) are composed of three different collagen types ie types II, IX and V/XI (Table $1)$. The collagen fibrils themselves are closely associated with a number of proteins including opticin, vitrin, fibulin- 1 and nidogen-1.5,6

Hyaluronan is a major component of the mammalian vitreous. It is a glycosaminoglycan that fills the space between the collagen fibrils. Hyaluronan-binding macromolecules including versican and link protein have been identified in vitreous, although these are present in a low molar ratio when compared to hyaluronan. ${ }^{7}$

The ILL is a basement membrane that, on one side, is attached to the Müller cell footplates on the inner surface of the retina and, on the other side, is attached to the cortical vitreous gel. The basement membrane components that have been identified in the ILL include type IV collagen, type XVIII collagen, laminin, nidogen-1, agrin and perlecan. ${ }^{8}$ Molecules of type IV collagen form a scaffold-like network that stabilises the basement membrane structure while laminin molecules form an independent scaffold as well as interacting with receptors in the cell membrane. ${ }^{9-11}$ Other macromolecules such as nidogen-1 or fibulin-1 most likely are involved in maintaining interactions between the different scaffolds found in basement membranes. ${ }^{12,13}$ Perlecan, agrin and type XVIII collagen are all heparan sulphate proteoglycans and interact extensively with other basement membrane components. ${ }^{14,15}$ 
Table 1 The collagens that form the heterotypic (mixed) fibrils in vitreous

\begin{tabular}{lcc}
\hline Collagen & $\begin{array}{l}\alpha \text {-Chains that assemble to } \\
\text { form collagen monomer }\end{array}$ & $\begin{array}{l}\text { Genes that encode } \\
\alpha \text {-chains }\end{array}$ \\
\hline Type II & $\alpha(1) \mathrm{II}$ & COL2A1 \\
Type IX & $\alpha(1) \mathrm{IX}$ & COL9A1 \\
& $\alpha(2) \mathrm{IX}$ & COL9A2 \\
Type V/XI & $\alpha(3) \mathrm{IX}$ & COL9A3 \\
& $\alpha(1) \mathrm{XI}$ & COL11A1 \\
& $\alpha(2) \mathrm{V}$ & COL5A2 \\
\hline
\end{tabular}

aThe third $\alpha$-chain in type $\mathrm{V} / \mathrm{XI}$ collagen has not been conclusively established.

Where are vitreous humour and inner limiting lamina components synthesised?

The source of vitreous and ILL macromolecules has been the subject of much speculation and it has only recently been clearly shown that these macromolecules can be synthesised by different cell types and synthesis can vary according to the developmental stage and possibly also with regard to different species. To date, most information has been derived from studies using mouse or chicken eyes and some caution should be exercised when extrapolating these data to human eyes. Furthermore, these studies use in situ hybridisation to detect mRNA expression, and it does not necessarily follow that the presence of a specific mRNA in a cell type will correlate with the biosynthesis of the corresponding protein.

\section{Source of vitreous collagens}

Using in situ hybridisation, several laboratories have studied mRNA expression of vitreous collagens type II and IX in the developing eye. ${ }^{16,17}$ Linsenmayer et $a l^{17}$ showed that, in the eye of the chicken embryo, type II collagen mRNA is expressed throughout the inner layer of the optic cup from embryonic days 3.5-5 and that type IX collagen (COL9A1) mRNA is expressed predominantly at the anterior tip of the developing optic cup adjacent to the developing lens. This represents the presumptive ciliary body region. By day 7, type II collagen mRNA expression becomes localised to the presumptive ciliary body and, by days 13-15, when the ciliary body is first formed, expression of both collagen type II and type IX mRNA is only seen in this region. In the chick eye, both types II and IX collagen mRNA are also expressed by the primary corneal stroma. ${ }^{18}$ Similarly, Dhawan and Beebe ${ }^{19}$ found that most of the COL9A1 expression during chicken development was located at the anterior tip of the optic cup. However, they noted some COL9A1 expression also in the optic cup before day 2.5 (stage
15) and low levels in the retina later during development.

We recently studied the expression of type II collagen and all three genes encoding IX collagen (ie COL9A1, COL9A2 and COL9A3) in the embryonic day 17.5 and adult mouse eye. ${ }^{20}$ In both the embryonic and adult mice the type IX collagen mRNA expression is predominantly localised to the ciliary body region. In the adult mouse eye this expression is specifically localised to the non-pigmented ciliary epithelium, although expression levels are lower than in the embryonic ciliary body. In addition, some COL9A1 expression is seen in the embryonic and adult retina and interestingly COL9A3 expression is seen in the embryonic choroid. Lui et $a^{21}$ analysed COL9A1 expression in the developing mouse eye and first observed expression at embryonic day 10.5 in the optic cup, but by embryonic day 16.5 the COL9A1 expression was observed exclusively over the inner layer of the presumptive ciliary epithelium. These authors could not demonstrate COL9A1 expression in the eye of mice older than 6 weeks. Thut et $a l^{22}$ also demonstrated COL9A1 expression exclusively in the region of the developing mouse ciliary body between embryonic day 14.5 and 2 days after birth, but they did not study the adult mouse. In agreement with these observations regarding the ciliary body, Ihanamäki et $a l^{23}$ localised type IX collagen by immunohistochemistry to the vitreous and associated with the basement membrane of the non-pigmented ciliary epithelium.

In the mouse, type II collagen mRNA is widely expressed in the embryonic and adult eye, expression being detected in the retina, sclera, cornea, lens and ciliary body. ${ }^{20}$ Similar observations were made in earlier work by Savontaus et al. ${ }^{24}$ Co-incident with the widespread expression of the COL2A1 gene, type II collagen was identified by immunohistochemistry in the vitreous and a weaker signal was observed in the retinal pigmented epithelium, inner retina, cornea and sclera of the adult mouse..$^{23,25}$

Taken together, these results suggest that vitreous type IX collagen in chicken and mouse (and therefore probably in all vertebrate species) predominantly originates from the ciliary body. In the chick and mouse, type II collagen is expressed by the ciliary body, but in the mouse other ocular tissues also express type II collagen so that its derivation in the vitreous remains uncertain. Summarising, it appears that the ciliary body, and in particular the nonpigmented ciliary epithelium, is the major source of at least one vitreous collagen. 


\section{Source of opticin}

Opticin is a member of the small leucine-rich repeat proteoglycan (SLRP) gene family that is highly expressed in the eye, but outside the eye expression levels in the adult mouse are very low. ${ }^{20}$ Opticin was initially identified as a glycoprotein closely associated with the collagen fibrils of the vitreous. ${ }^{5}$ In other tissues, other SLRP family members have been shown to bind to collagen fibrils and to regulate collagen fibril diameter and spacing. ${ }^{26}$ Opticin may serve a similar function. In situ hybridisation of the developing mouse eye showed that opticin expression is confined to the ciliary body region of the optic cup during development and to the posterior non-pigmented ciliary epithelium in the adult mouse. ${ }^{20}$ Opticin expression was observed at the same time as ciliary body differentiation begins (embryonic day 15.5) and, unlike the collagen genes, continued high levels of expression were seen in the adult mouse eye (Figure 1). Similarly, in situ hybridisation analysis of an adult human eye demonstrated a strong signal that was confined to the non-pigmented ciliary epithelium (Figure 2). The expression levels were high both in the pars plana (Figure 2: upper panels) and posterior pars plicata (Figure 2: lower panels), but the signal became less intense towards the anterior part of the pars plicata. These results appear to conflict with results showing that opticin is highly expressed in libraries prepared from the adult human iris. ${ }^{27,28}$ In the recently released data from NEIBank (http://neibank. nei.nih.gov/index.shtml) opticin was reported to represent the sixth commonest clone in an adult iris library. We have no simple explanation for the discrepancy between these results and our in situ results except to suggest that tissue from the ciliary body may have been inadvertently included in the iris libraries during dissection. Nevertheless, the present results taken in toto suggest that the adult mammalian eye continues to synthesise and secrete high levels of opticin from the ciliary body even when the synthesis of vitreous collagens has largely ceased. In the mouse this is particularly remarkable given the limited
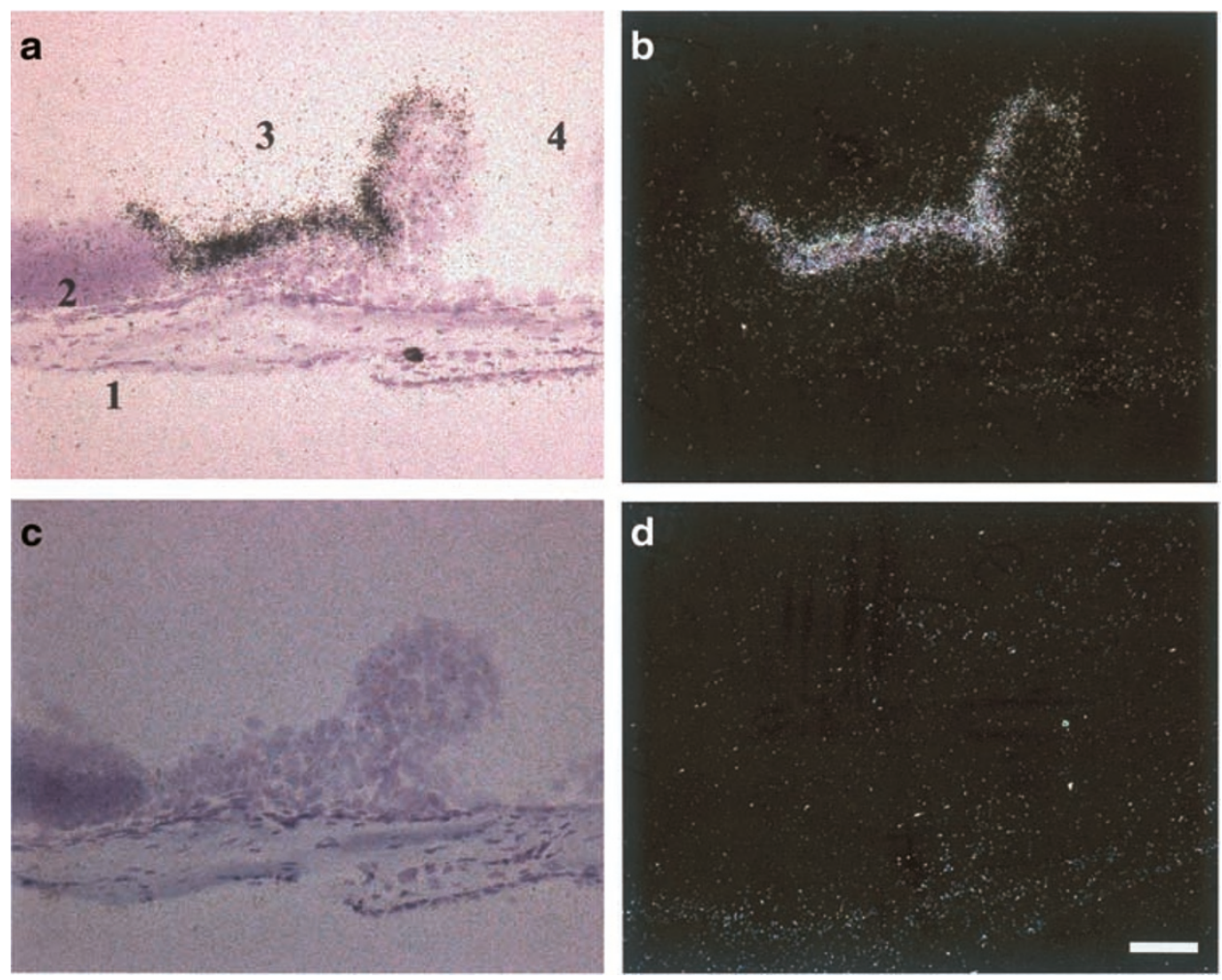

Figure 1 Analysis of opticin expression by in situ hybridisation in an adult mouse eye. In situ hybridisation to show mRNA expression for opticin in the region of the ciliary body of an adult, albino mouse eye was performed as described previously. ${ }^{20}$ All animals were treated humanely in accordance with the Association of Research in Vision and Ophthalmology Resolution on the Use of Animals in Research. (a) and (b) Antisense probe for opticin: bright (a) and dark (b) field. (c) and (d) Sense probe for opticin: bright (c) and dark (d) field. (a) 1 = sclera; 2 = retina; 3 = ciliary body, pars plana; 4 = ciliary body, pars plicata. Note that a positive signal is only observed with the antisense probe in the non-pigmented ciliary epithelium which extends from the retina along the pars plana to the posterior half of the pars plicata. In the adult mouse eye this is the only location where significant expression of opticin can be detected. Bar $=50 \mu \mathrm{m}$. 

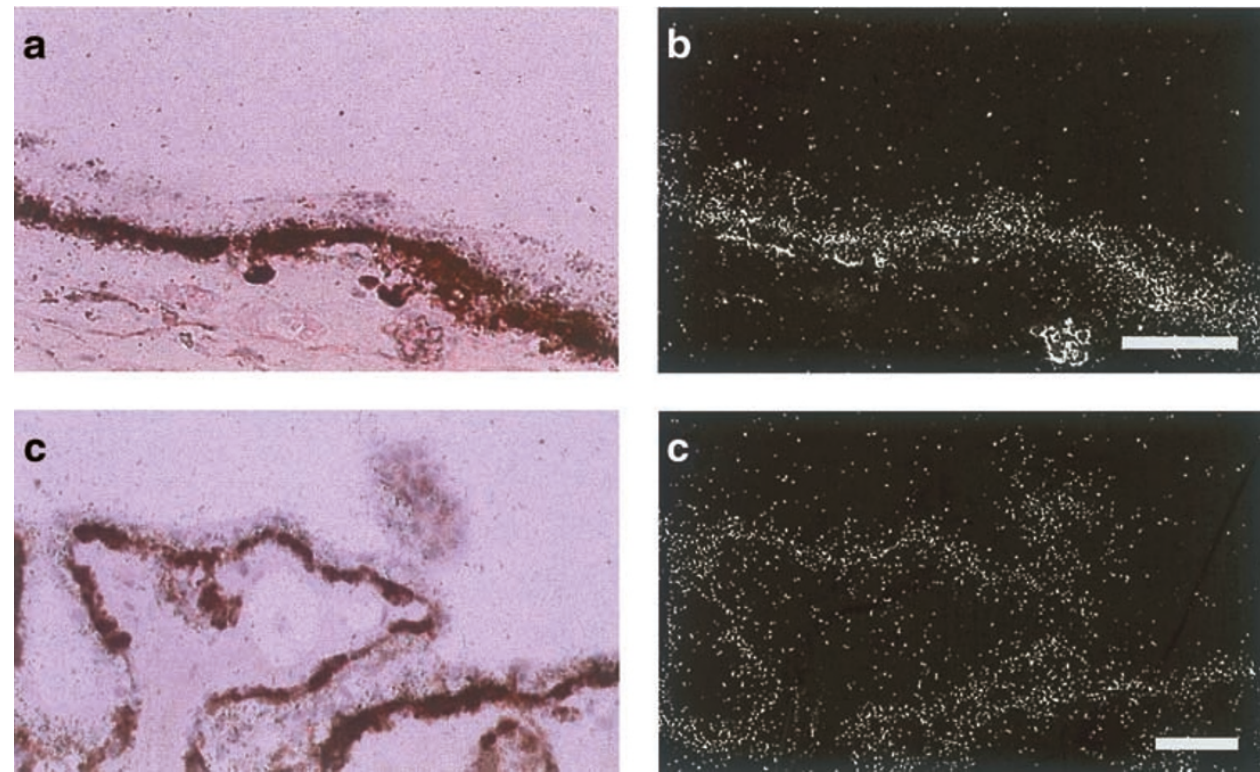

Figure 2 Analysis of opticin expression by in situ hybridisation in an adult human eye. Sections were cut from a wax-embedded, paraformaldehyde-fixed adult (age 45 years) human eye. A 400-bp fragment of human opticin cDNA was cloned and used to generate $\left[{ }^{35} \mathrm{~S}\right] \alpha$-dCTP labelled anti-sense and sense riboprobes. ${ }^{61}$ The sections were digested with proteinase $\mathrm{K}$, and acetylated prior to hybridisation, washing and autoradiography. ${ }^{61}$ The sections were counterstained with $\mathrm{H}$ and E. (a) and (b) Bright and dark field views respectively of the pars plana. (c) and (d) Bright and dark field views of the posterior part of the pars plicata. Opticin message was observed specifically in the non-pigmented ciliary epithelium. In the anterior parts of the pars plicata the opticin signal from the non-pigmented ciliary epithelium became much less intense. A weaker signal was observed in the pigment epithelium with the antisense and sense probes (suggesting non-specific labeling), and no labeling of the non-pigmented ciliary epithelium was seen using the sense probe (data not shown). Bar $=150 \mu \mathrm{m}$.

amounts of vitreous in the adult mouse eye with most of the available space being occupied by the lens.

Recent results described above suggest that opticin is a specialised SLRP specifically for the vitreous with perhaps more than a simple structural function. ${ }^{20}$ Furthermore, to date, we have not found evidence for other SLRPs in the vitreous. Several of the SLRPs are substituted with chondroitin/dermatan sulphate chains and none of these could be identified in bovine vitreous. ${ }^{5,7}$ Furthermore, neither decorin nor biglycan could be detected even by Western blotting (unpublished observations). Recently, we have determined that the opticin gene is located on chromosome 1q32 in a cluster with two other SLRPs called fibromodulin and PRELP. ${ }^{20,29}$ Further analysis of the public genomic databases presently available (GENBANK, http://www.ncbi.nlm.nih.gov: ENSEMBL, http:/ / ensembl.org/genome/central; Jim Kent, http:/ /www.cse.ucsc.edu/kent/) showed that the SLRP family occurs as three or perhaps four clusters both for the mouse and human genome. Opticin is a Class 3 SLRP $^{30}$ as are epiphycan (chromosome 12q23) and osteoglycin (chromosome 9q22). These three SLRPs have widely differing locations and presumably somewhat differing functions. ${ }^{29}$ How development of such specialised functions could have arisen after two rounds of gene duplication is presently not understood. ${ }^{31-35}$ However, the interrelationships between the SLRPs during evolution are likely to become clearer as members of the SLRP family are identified in lower organisms such as zebrafish, ${ }^{36}$ for which the genome is presently being sequenced.

\section{Source of vitrin}

A second connective tissue macromolecule weakly associated with the collagen fibrils was identified in the vitreous of young calves grown for the veal industry but not in significant amounts in adult cows. ${ }^{6}$ Cloning of this molecule (called vitrin) demonstrated that it is closely related to a protein called $\mathrm{COCH}^{37,38}$ with a single LCCL motif, ${ }^{39,40}$ followed by two von Willebrand Factor A (vWA) domains that represent a known collagen-binding motif. ${ }^{41}$ In situ hybridisation of the developing mouse eye shows that vitrin is exclusively synthesised by the lens ${ }^{42}$ and this is supported by recent analyses of human cDNA libraries prepared from adult human eyes (NEIBank). Of the wide variety of eye tissues that were analysed by DNA sequencing, cDNA clones for vitrin were found only in a lens-specific library. The function of this connective tissue macromolecule is at present uncertain, but this 
observation reinforces earlier statements in this review that connective tissue macromolecules present in vitreous may be derived from more than one tissue.

\section{Non-collagenous vitreous components}

As well as containing structural macromolecules, the vitreous contains a number of other proteins/glycoproteins many of which are poorly defined. Some of these are derived from serum, such as serum albumin, but others are synthesised within the eye and appear to be largely derived from the ciliary body. ${ }^{43}$ Transferrin, a major glycoprotein present in the vitreous, was recently shown to be synthesised by the ciliary body epithelium. ${ }^{44}$

\section{Inner limiting lamina}

The inner limiting lamina is formed on the footplates of the retina Müller cell and it has been generally assumed, although never proven, that its structural macromolecules were derived from these cells. However, recent work by Halfter et al ${ }^{45,46}$ suggests that this is not the case, at least in the embryonic chick eye. These authors presented evidence that only agrin is derived from the retina and that other components are secreted into the anterior vitreous humour and traverse the vitreous cavity to assemble on Müller cell footplates. This may explain why we have observed nidogen-1 and fibulin-1 associated with vitreous collagen fibrils, ${ }^{6}$ since these proteins are likely to be involved in basement membrane assembly. The precise cellular source of all basement membrane components has yet to be established but possibilities include both the non-pigmented ciliary epithelium and the lens. In the chicken, nidogen-1, type XVIII collagen and the laminin $\gamma$ chain can be detected in the ciliary body by in situ hybridisation. ${ }^{45,46}$ The same authors have also recently shown that binding of soluble laminin-1 to Müller cell footplates is critical for the initiation of ILL assembly. ${ }^{46}$

\section{Induction of the ciliary body}

It is of interest that opticin expression is first detected at the time of initiation of ciliary epithelial development from the rim of the optic cup. ${ }^{47,48}$ It is possible that this occurs from the inductive influence of the lens, ${ }^{48,49}$ since at this time, it is in close proximity to the ciliary body. At present, we do not know if the lens is responsible for the induction of opticin biosynthesis but recent data showing induction in the ciliary body of Tgfb1i4 (transforming growth factor beta 1 induced transcript 4) and Ptmb4 (prothymosin beta 4) by the lens would support this possibility. ${ }^{22}$ At present, the nature of the inducing molecule(s) produced by the lens is also unknown although induction of Tgfb1i4 and Ptmb4 can be achieved in a simple cell culture system where the lens is placed in juxtaposition to the retina. ${ }^{22}$ That the lens (and presumably macromolecules secreted by the lens) play a central role in development of the posterior chamber including the retina is clearly demonstrated by experiments involving lens transplantation in blind cave fish ${ }^{50}$ and by inhibition specifically of lens development in the mouse eye. ${ }^{51-53}$ Furthermore, the blood vessels of the tunica vasculosa lentis appear to be dependent upon vascular endothelial growth factor secretion by the lens as decreased expression levels are associated with regression of this system at embryonic day 17.5 in the mouse..$^{54}$

\section{New roles for the ciliary epithelium}

The involvement of the non-pigmented epithelium of the anterior ciliary body (pars plicata) in the synthesis of the aqueous humour has been extensively investigated and will not be discussed here. ${ }^{55}$ However, the synthesis of many components of the vitreous by the non-pigmented epithelium of the posterior ciliary body (posterior pars plicata and pars plana) has not been emphasised previously although earlier work suggested that it also had a secretory function. ${ }^{56}$ Morphologically, the anterior and posterior non-pigmented ciliary epithelia appear similar ${ }^{57}$ and yet are apparently fulfilling different functions. It is of special interest that the pigmented ciliary epithelium of vertebrates apparently contains precursor cells (stem cells) for the retina, ${ }^{58,59}$ and that the human ocular nonpigmented ciliary epithelium is capable of synthesising macromolecules required for phototransduction which may be used for circadian entrainment tasks. ${ }^{60}$

\section{Conclusion}

Our results, ${ }^{20}$ together with the recent results from other groups suggest that the posterior non-pigmented ciliary epithelium of the mammalian eye may be the source of many connective tissue macromolecules present in the vitreous as well as being a potential source of several structural macromolecules that assemble to form the ILL.

\section{Acknowledgements}

Supported in part by grant R37 AR30481 from The National Institutes of Health, EyeSight Foundation of Alabama and Fight for Sight. PNB is a Wellcome Trust 
Senior Research Fellow in Clinical Science. The authors would like to thank David McLeod, FRCOphth, for critical reading of the manuscript.

\section{References}

1 Lazarus HS, Hageman GS. In situ characterization of the human hyalocyte. Arch Ophthalmol 1994; 112: 1356-1362.

2 Bos KJ, Holmes DF, Meadows RS, Kadler KE, McLeod D, Bishop PN. Collagen fibril organisation in mammalian vitreous by freeze etch/rotary shadowing electron microscopy. Micron 2001; 32: 301-306.

3 Bishop PN. Structural macromolecules and supramolecular organisation of the vitreous gel. Prog Ret Eye Res 2000; 19: 323-344.

4 Mayne R, Brewton RG, Ren ZX. The vitreous body and zonular apparatus. In: Harding JJ (ed). Biochemistry of the Eye, 1st edn. Chapman and Hall: London, 1997, pp 135143.

5 Reardon AJ, Le Goff M, Briggs MD, McLeod D, Sheehan JK, Thornton DJ, Bishop PN. Identification in vitreous and molecular cloning of opticin, a novel member of the family of leucine-rich repeat proteins of the extracellular matrix. J Biol Chem 2000; 275: 2123-2129.

6 Mayne R, Ren Z-X, Liu J, Cook T, Carson M, Narayana S. VIT-1: the second member of a new branch of the vWFA superfamily. Biochem Soc Trans 1999; 27: 832-835.

7 Reardon A, Heinegrd D, McLeod D, Sheehan JK, Bishop $\mathrm{PN}$. The large chondroitin sulphate proteoglycan versican in mammalian vitreous. Matrix Biol 1998; 17: 325-333.

8 Mayne R. The eye. In: Royce P, Steinmann B (eds). Connective Tissue and its Heritable Disorders. Wiley-Liss: New York, 2001, pp 131-141.

9 Timpl R. Macromolecular organization of basement membranes. Curr Opin Cell Biol 1996; 8: 618-624.

10 Colognato $H$, Yurchenco PD. Form and function: the laminin family of heterotrimers. Dev Dyn 2000; 218: 213 234

11 Erickson AC, Couchman JR. Still more complexity in mammalian basement membranes. J Histochem Cytochem 2000; 48: 1291-1306.

12 Ries A, Göhring W, Fox JW, Timpl R, Sasaki T. Recombinant domains of mouse nidogen- 1 and their binding to basement membrane proteins and monoclonal antibodies. Eur J Biochem 2001; 268: 5119-5128.

13 Kostka G, Giltay R, Bloch W, Addicks K, Timpl R, Fassler $\mathrm{R}$, Chu ML. Perinatal lethality and endothelial cell abnormalities in several vessel compartments of fibulin-1deficient mice. Mol Cell Biol 2001; 505: 173-178.

14 Hopf M, Göhring W, Kohfeldt E, Yamada Y, Timpl R. Recombinant domain IV of perlecan binds to nidogens, laminin-nidogen complex, fibronectin, fibulin-2 and heparin. Eur J Biochem 1999; 259: 917-925.

15 Hopf M, Göhring W, Mann K, Timpl R. Mapping of binding sites for nidogens, fibulin-2, fibronectin and heparin to different IG modules of perlecan. J Mol Biol 2001; 311: 529-541.

16 Cheah KSE, Lau ET, Au PKC, Tam PPL. Expression of mouse alpha1(II) collagen gene is not restricted to cartilage during development. Development 1991; 111: 945953.

17 Linsenmayer TF, Gibney E, Gordon MK, Marchant JK, Hayashi M, Fitch JM. Extracellular matrices of the developing chick retina and cornea. Localization of
mRNAs for collagen types II and IX by in situ hybridisation. Invest Ophthalmol Vis Sci 1990; 31: 12711276.

18 Linsenmayer TF, Fitch JM, Gordon MK, Cai CX, Igoe F, Marchant JK, Birk DE. Development and roles of collagenous matrices in the embryonic avian cornea. Prog Ret Eye Res 1998; 17: 231-265.

19 Dhawan RR, Beebe DC. Differential localization of collagen type IX isoform messenger RNAs during early ocular development. Invest Ophthalmol Vis Sci 1994; 35: 470-478.

20 Takanosu M, Boyd TC, Le Goff M, Henry SP, Zhang Y, Bishop PN, Mayne R. Structure, chromosomal location and tissue-specific expression of the mouse opticin gene. Invest Ophthalmol Vis Sci 2001; 42: 2202-2210.

21 Liu CY, Olsen BR, Kao WW. Developmental patterns of two alpha 1(IX) collagen mRNA isoforms in mouse. Dev Dyn 1993; 198: 150-157.

22 Thut CJ, Rountree RB, Hwa M, Kingsley DM. A largescale in situ screen provides molecular evidence for the induction of eye anterior segment structures by the developing lens. Dev Biol 2001; 231: 63-76.

23 Ihanamäki T, Salminen H, Säämänen AM, Pelliniemi LJ, Hartmann DJ, Sandberg-Lall M, Vuorio E. Age-dependent changes in the expression of matrix components in the mouse eye. Exp Eye Res 2001; 72: 423-431.

24 Savontaus M, Ihanamäki T, Perala M, Metsaranta M, Sandberg-Lall M, Vuorio E. Expression of type II and IX collagen isoforms during normal and pathological cartilage and eye development. Histochem Cell Biol 1998; 110: $149-159$.

25 Wood A, Ashhurst DE, Corbett A, Thorogood P. The transient expression of type II collagen at tissue interfaces during mammalian craniofacial development. Development 1991; 111: 955-968.

26 Iozzo RV. The biology of the small leucine-rich proteoglycans: functional network of interactive proteins. J Biol Chem 1999; 274: 18843-18846.

27 Hobby P, Wyatt K, Gan W, Bernstein S, Tomarev S, Slingsby C, Wistow G. Cloning, modelling, and chromosomal localization for a small leucine-rich repeat proteoglycan (SLRP) family member expressed in human eye. Mol Vis 2000; 6: 72-78.

28 Friedman JS, Ducharme R, Raymond V, Walter MA. Isolation of a novel iris-specific and leucine-rich repeat protein (oculoglycan) using differential selection. Invest Ophthalmol Vis Sci 2000; 41: 2059-2066.

29 Henry SP, Takanosu M, Boyd TC, Mayne PM, Eberspaecher H, Zhou W et al. Expression pattern and gene characterization of asporin. J Biol Chem 2001; 276: 12212-12221.

30 Hocking AM, Shinomura T, McQuillan DJ. Leucine-rich repeat glycoproteins of the extracellular matrix. Matrix Biol 1998; 17: 1-19.

31 Ohta T. Simulating evolution by gene duplication. Genetics 1987; 115: 207-213.

32 Walsh JB. How often do duplicated genes evolve new functions? Genetics 1995; 139: 421-428.

33 Force A, Lynch M, Pickett FB, Amores A, Yan Y-L, Postlethwait J. Preservation of duplicate genes by complementary, degenerative mutations. Genetics 1999; 151: 1531-1545.

34 Massingham T, Davies LJ, Liò P. Analysing gene function after duplication. BioEssays 2002; 23: 873-876. 
35 Wagner A. Birth and death of duplicated genes in completely sequenced eukaryotes. Trend Genet 2001; 17: 237-239.

36 Shintani S, Sato A, Toyosawa S, O'hUigin C, Klein J. Biglycan-like extracellular matrix genes of agnathans and teleosts. J Mol Evol 2000; 51: 363-373.

37 Robertson NG, Resendes BL, Lin JS, Lee C, Aster JC, Adams JC, Morton CC. Inner ear localization of mRNA and protein products of $\mathrm{COCH}$, mutated in the sensorineural deafness and vestibular disorder, DFNA9. Hum Molec Genet 2001; 10: 2493-2500.

38 Robertson NG, Lu L, Heller S, Merchant SN, Eavey RD, McKenna $\mathrm{M}$ et al. Mutations in a novel cochlear gene cause DFNA9, a human nonsyndromic deafness with vestibular dysfunction. Nat Genet 1998; 20: 299-303.

39 Trexler M, Bányai L Patthy L. The LCCL module. Eur J Biochem 2000; 267: 5751-5757.

40 Liepinsh E, Trexler M, Kaikkonen A, Weigelt J, Bányai L, Patthy L, Otting G. NMR structure of the LCCL domain and implications for DFNA9 deafness disorder. EMBO J 2001; 20: 5347-5353.

41 Emsley J, Knight CG, Farndale RW, Barnes MJ, Liddington RC. Structural basis of collagen recognition by integrin alpha2beta1. Cell 2000; 101: 47-56.

42 Mayne R, Cook T, Takanosu M. Vit-1 is synthesized by the lens during the development of the mouse eye. Invest Ophthalmol Vis Sci 2000; 41: S868.

43 Haddad A, Laicine EM, de Almeida JC, Costa MS. Partial characterization, origin and turnover of glycoproteins of the rabbit vitreous body. Exp Eye Res 1990; 51: 139-143.

44 Rodrigues ML, Filho RB, Laicine EM, Haddad A. Transferrin production by the ciliary body of rabbits: a biochemical and immunocytochemical study. Curr Eye Res 1998; 17: 694-699.

45 Halfter W, Dong S, Schurer B, Osanger A, Schneider W, Ruegg M, Cole GJ. Composition, synthesis, and assembly of the embryonic chick retinal basal lamina. Dev Biol 2000; 220: 111-128.

46 Halfter W, Dong S, Balasubramani M, Bier ME. Temporary disruption of the retinal basal lamina and its effect upon retinal histogenesis. Dev Biol 2001; 238: 79-96.

47 Streeten BW. The ciliary body. In: Tasman W, Jaeger E (eds). Duane's Foundations of Clinical Ophthalmology. Ocular Anatomy, Embryology and Teratology. Lippincott: Philadelphia, 1999, pp 1-38.

48 Beebe DC. Development of the ciliary body: a brief review. Trans Ophthalmol Soc UK 1986; 105: 123-130.
49 Harrington L, Klintworth GK, Secor TE, Breitman ML. Developmental analysis of ocular morphogenesis in $\alpha \mathrm{A}$ crystallin/diphtheria toxin transgenic mice undergoing ablation of the lens. Dev Biol 1991; 148: 508-516.

50 Yamamoto Y, Jeffery WR. Central role for the lens in cave fish eye degeneration. Science 2000; 289: 631-633.

51 Ashery-Padan R, Marquardt T, Zhou X, Gruss P. Pax6 activity in the lens primordium is required for lens formation and for correct placement of a single retina in the eye. Genes \& Dev 2000; 14: 2701-2711.

52 Semina EV, Murray JC, Reiter R, Hrstka RF, Graw J. Deletion in the promoter region and altered expression of Pitx3 homeobox gene in aphakia mice. Hum Mol Gen 2000; 11: $1575-1585$.

53 Rieger DK, Reichenberger E, McLean W, Sidow A, Olsen BR. A double-deletion mutation in the Pit $x 3$ gene causes arrested lens development in aphakia mice. Genomics 2001; 72: 61-72.

54 Mitchell CA, Risau WE, Drexler HCA. Regression of vessels in the tunica vasculosa lentis is initiated by coordinated endothelial cell apoptosis: a role for vascular endothelial growth factor as a survival factor for endothelium. Dev Dyn 1998; 213: 322-333.

55 Coca-Prados M, Escribano J, Ortego J. Differential gene expression in the human ciliary epithelium. Prog Retin Eye Res 1999; 18: 403-429.

56 Fine BS, Zimmerman LE. Light and electron microscopic observations on the ciliary epithelium in man and rhesus monkey. Invest Ophthalmol 1963; 2: 105-137.

57 Oyster CW. The Human Eye: Structure and Function. Sinauer Associates: Sunderland, Massachusetts, 1999

58 Tropepe V, Coles BL, Chiasson BJ, Horsford DJ, Elia AJ, McInnes RR, van der Kooy D. Retinal stem cells in the adult mammalian eye. Science 2000; 287: 2032-2036.

59 Ahmad I, Tang L, Pham H. Identification of neural progenitors in the adult mammalian eye. Biochem Biophys Res Commun 2000; 270: 517-521.

60 Bertazolli-Filho R, Ghosh S, Huang W, Wollmann G, Coca-Prados M. Molecular evidence that human ocular ciliary epithelium expresses components involved in phototransduction. Biochem Biophys Res Commun 2001; 284: 317-325.

61 Downey SE, Hoyland J, Freemont AJ, Knox F, Walls J, Bundred NJ. Expression of the receptor for parathyroid hormone-related protein in normal and malignant breast tissue. J Pathol 1997; 183: 212-217. 